\title{
Evaluating the Association between Clinical Characteristics with Progression-Free Survival and 3-Year Survival in Patients with Epithelial Ovarian Cancer
}

\author{
Brahmana Askandar Tjokroprawiro*, Sonny Fadli, Budiono
}

Department of Obstetric Gynecology, Faculty of Medicine, Universitas Airlangga, RSUD dr. Soetomo, Surabaya, Indonesia

\section{ARTICLE INFO}

Received : 13 December 2020

Reviewed : 23 February 2021

Accepted : 22 June 2021

Keywords:

ovarian cancer, progression-free survival, 3-year survival

\author{
*Corresponding author: \\ Sonny Fadli \\ Department of Obstetric Gynecology, \\ Faculty of Medicine, Universitas \\ Airlangga, RSUD dr. Soetomo, \\ Surabaya, Indonesia \\ doktersonny@gmail.com
}

\begin{abstract}
Background: This study was conducted to determine the association between clinical characteristics, progression-free survival (PFS), and 3-year survival in patients with epithelial ovarian cancer who underwent surgery in 2016-2017 at RSUD Dr. Soetomo. This study was carried out with the hope of contributing to services for patients with epithelial ovarian cancer to improve outcomes at RSUD Dr. Soetomo.
\end{abstract}

\begin{abstract}
Methods: This retrospective analytic study used medical record data. Survival analysis was done employing Kaplan-Meier and log-rank tests, while Cox regression was utilized to analyze characteristics, recurrence, and mortality.
\end{abstract}

Results: In 2016-2017, 56 patients with epithelial ovarian cancer met the inclusion criteria. Clinical characteristics of residue, stage had significant associations with PFS (P-value of 0.007 and P-value of 0.005 , respectively). Residue, stage, histopathology, and the number of chemotherapy cycles had significant associations with 3-year survival ( $P$-value of $0.001, P$-value of $<0.001$, P-value of $<0.001, \mathrm{P}$-value of 0.031 , respectively). Recurrence and stage had a significant association with the following hazard ratios: stage I HR: 1 (CI 95\%, P-value 0.145), stage II HR: 6.5 (Cl 95\% 0.6-74.7, P-value 0.134), stage III HR: 12.2 (Cl 95\% 1.4-105.4, P-value 0.061), and stage IV HR: 10.4 (Cl 95\% 0.8-120.8, P-value 0.061). Mortality had significant associations with stage, histopathology, and the number of chemotherapy cycles, with hazard ratios as follows: stage IV HR: 43.6 (Cl 95\% 4.5-417.9, P-value 0.001), seromucinous histopathology HR: 20.1 (Cl 95\% 0.9-408.6, P-value 0.026), chemotherapy cycles < $3 \mathrm{HR}: 3.6$ (Cl 95\% 1.2-11.5, P-value 0.459), and > 3 HR: 1 (Cl 95\%, P-value 0.028).

Conclusions: Residue and stage had statistically significant associations with PFS and can be predictors for disease recurrence. Residue, stage, histopathology, number of chemotherapy cycles had significant associations with 3-year survival, but only the latter three characteristics can be predictors for mortality.

\section{INTRODUCTION}

In 2018, ovarian cancer accounted for approximately 295,414 new cases and 184,799 deaths worldwide [1]. Ovarian cancer usually appears at an advanced stage when the 5-year survival is only $30.2 \%$. Besides, only $16 \%$ are diagnosed with localized (stage 1 ) tumors when the 5 -year survival is $92.6 \%$. Interestingly, 5-year survival ranges from $30-40 \%$ worldwide and has only experienced a very small increase (2-4\%) since 1995 [2].

Histopathology data in the Gynecology-Oncology Outpatient Clinic of RSUD Dr. Soetomo has been well documented since 2014. Since that time, ovarian cancer was diagnosed in 164 cases (14\%) in 2014, 196 cases $(17 \%)$ in 2015 , and 216 cases (15.6\%) in 2016. In 2017, $87.4 \%$ of cases were epithelial, while $12.5 \%$ were nonepithelial. Besides, most of the ovarian cancer patients in RSUD Dr. Soetomo, who died, were initially diagnosed with stage III (17 patients; 39.5\%) and stage IV (seven patients; $16.2 \%)$ [3].

Therefore, this study was conducted to determine the association between clinical characteristics, PFS, and 3-year survival in patients with epithelial ovarian cancer 
who underwent surgery in 2016-2017 at RSUD Dr. Soetomo. We hope that this study will contribute to service guidelines for patients with epithelial ovarian cancer to improve outcomes at RSUD Dr. Soetomo.

\section{METHODS}

This study was conducted using a retrospective cohort design with medical record data from the GynecologyOncology Outpatient Clinic at RSUD Dr. Soetomo collected in October 2020. Inclusion criteria were epithelial ovarian cancer patients at any stage of disease who underwent surgery from September 2016 to September 2017 at RSUD Dr. Soetomo and whose histopathology examinations were carried out at RSUD Dr. Soetomo. The exclusion criterion was incomplete medical records.

The clinical characteristics assessed included age, stage, residue, histopathology, grade, and the number of chemotherapy cycles. The diagnosis of epithelial ovarian cancer was determined based on histopathology results by the pathologist, using the 2014 WHO classification [4]. Histopathology was classified as serous, mucinous, endometrioid, clear cell, or seromucinous. Meanwhile, the grade was categorized as welldifferentiated (G1), moderately differentiated (G2), or poorly differentiated (G3).

Age was defined as the age at which the patient underwent surgery, divided into $<60$ years and $>60$ years. Meanwhile, the ovarian cancer stage was determined clinically by the surgeon according to the 2014 International Federation of Gynecology and Obstetrics (FIGO) staging [5]. The residue was termed as residual tumor after the surgery staging by evaluating a large clinical residual tumor. Residue was grouped as no residue, residue $<1 \mathrm{~cm}$, or residue $>1 \mathrm{~cm}$. The number of chemotherapy cycles was defined as the postoperative administration of first-line platinum-based regimen as the adjuvant therapy and classified as none, $<3$, or $>3$ chemotherapy cycles.

Moreover, the day of surgery was the starting point of a 3-year observation until the endpoint, such as recurrence to analyze PFS or patient death to analyze 3-year survival. Recurrence was identified as the discovery of residual mass based on manual vaginal examination, ultrasound, or abdominal CT scan during follow-up. Meanwhile, PFS was defined as the time interval from the day of surgery until the day of recurrence. If no recurrence was found, PFS was calculated from the day of surgery to the day of loss to follow-up or the last patient clinic visit. The endpoint used to analyze 3-year survival was death. In addition, the 3-year survival was specified as the relative survival over three years, calculated from the day of surgery to the time of death or the last patient visit if she was still alive.
Furthermore, censored data was described as a partial observance of survival time, but not until recurrence or death occurred. Patient loss to follow up, changing to a different clinic or hospital, led to censoring data. A patient was considered to have dropped out if the treatment was discontinued, such as refusal of chemotherapy despite indications.

The characteristic clinical data were descriptively then analyzed utilizing SPSS software to obtain PFS and 3-year survival percentages, followed by Kaplan-Meier and log-rank analyses to obtain PFS (mean, median, and P-value) and 3-year survival (mean, median, and $\mathrm{P}$-value). Besides, Cox regression, univariate, and multivariate analyses were employed to assess possible associations between characteristics, recurrence, and mortality (hazard ratio and P-value).

\section{RESULTS}

In 2016-2017, 128 patients had a histopathological diagnosis of epithelial ovarian cancer, of whom 56 met the inclusion criteria. A total of 72 patients were excluded because of incomplete medical records.

\section{Progression-free survival analysis}

The PFS analysis results are shown in Table 1 . Residue and stage had significant associations with PFS (P-value of 0.007, P-value of 0.005, respectively). However, age, histopathology, grade, and the number of chemotherapy cycles had no significant association with PFS.

Despite the significant association between residue and PFS, the mean and median PFS could not be analyzed, as none of the patients without residue experienced a recurrence. Patients with residue $>1 \mathrm{~cm}$ had a median PFS of 22 months (Figure 1). However, mean PFS could not be determined because the two patients with residue $\leq 1 \mathrm{~cm}$ were included in the censored data.

In addition, Kaplan-Meier analysis revealed that stage had a statistically significant association with PFS. In patients with stage I, the median PFS value could not be determined because the stage I curve did not exceed the $50 \%$ PFS probability value (Figure 2). Patients with stage II, III, and IV had median PFS of 28 months, 22 months, and 25 months, respectively. The mean PFS for stages I, II, III, and IV values were 35.6 months, 25.6 months, 22.9 months, and 23.1 months.

Further analysis was carried out on the clinical characteristics of recurrence using Cox regression analysis to obtain hazard ratios (HR), as shown in Table 2 .

Based on the results above, residue and stage characteristics had statistically significant associations with PFS and can be predictors of disease recurrence. However, age, histopathology, grade, and the number of chemotherapy cycles had no such associations. 


\section{3-Year Survival Analysis}

The results of the 3-year survival analysis are presented in Table 3. Residue, stage, histopathology, and the number of chemotherapy cycles had statistically significant associations with 3-year survival ( $P$-value of $0.001,<0.001,<0.001$, and 0.031, respectively). However, age and grade had no significant association with 3-year survival.

Moreover, patients with no residue had the highest mean survival of 31.2 months and 3-year survival of $56.8 \%$. Meanwhile, patients with residue $\leq 1 \mathrm{~cm}$ had a mean survival of 20.5 months and 3-year survival of $50 \%$. Besides, patients with residue $>1 \mathrm{~cm}$ had the lowest mean survival of 16.7 months and 3-year survival of $21.4 \%$.
Patients with stage I had the highest mean survival of 32.9 months and 3-year survival of $80.8 \%$. Besides, patients with stage II had a mean survival of 28.1 months and 3-year survival of $55.6 \%$, while patients with stage III had a mean survival of 20.8 months and 3-year survival of $17.6 \%$. Lastly, patients with stage IV had the lowest mean survival of 14.5 months and a 3 -year survival value of $25.0 \%$. Figures 3-6 show the 3-year survival probability for residue, stage, histopathology, and number of chemotherapy cycles. Regression analysis to obtain HRs, as shown in Table 4.

Based on the results above, residue, stage, histopathology, and the number of chemotherapy cycles had significant associations with 3-year survival, but only the stage, histopathology, and the number of chemotherapy cycles can be useful predictors for mortality.
Table 1. Kaplan-Meier analysis and log-rank test on PFS

\begin{tabular}{|c|c|c|c|c|c|}
\hline Characteristics & No recurrence & $\begin{array}{c}\text { 3-year PFS, } \\
\%\end{array}$ & $\begin{array}{c}\text { Mean PFS, } \\
\text { months }(95 \% \mathrm{Cl})\end{array}$ & $\begin{array}{c}\text { Median PFS, } \\
\text { months (95\% Cl) }\end{array}$ & $\mathbf{P}$ \\
\hline \multicolumn{6}{|l|}{ Age: } \\
\hline$\leq 60$ y.o. & 27 & 73 & $29.2(25.2-33.2)$ & $36(-)$ & 0.634 \\
\hline$>60$ y.o. & 16 & 84.2 & $31.5(26.8-36.2)$ & $34(3.2-64.7)$ & \\
\hline \multicolumn{6}{|l|}{ Residue: } \\
\hline No residue & 34 & 85.0 & - & - & 0.007 \\
\hline$\leq 1 \mathrm{~cm}$ & 2 & 100 & - & - & \\
\hline$>1 \mathrm{~cm}$ & 7 & 50.0 & - & - & \\
\hline \multicolumn{6}{|l|}{ Stage: } \\
\hline 1 & 25 & 96.2 & $35.6(34.8-36.3)$ & - & 0.005 \\
\hline II & 7 & 77.8 & $25.6(19.4-31.7)$ & $28(1.2-54.8)$ & \\
\hline III & 9 & 52.9 & $22.9(15.9-29.9)$ & $22(15.8-28.2)$ & \\
\hline IV & 2 & 50.0 & $23.1(9.4-36.8)$ & $25(0.000-60.9)$ & \\
\hline \multicolumn{6}{|l|}{ Histopathology: } \\
\hline Serous & 11 & 68.8 & & & \\
\hline Mucinous & 15 & 93.8 & - & - & 0.613 \\
\hline Clear cell & 6 & 75.0 & - & - & \\
\hline Endometrioid & 9 & 64.3 & - & - & \\
\hline Seromucinous & 2 & 100 & $\begin{array}{l}- \\
-\end{array}$ & $\begin{array}{l}- \\
-\end{array}$ & \\
\hline \multicolumn{6}{|l|}{ Grade: } \\
\hline 1 & 25 & 83.3 & $30.5(26.1-34.9)$ & - & 0.537 \\
\hline II & 8 & 66.7 & $\begin{array}{l}30.5(26.1-34.9) \\
25.3(18.3-32.2)\end{array}$ & - & \\
\hline III & 10 & 71.4 & $\begin{array}{l}25.3(18.3-32.2) \\
31.7(26.7-36.8)\end{array}$ & 36 & \\
\hline \multicolumn{6}{|l|}{$\begin{array}{l}\text { Number of } \\
\text { chemotherapy cycles: }\end{array}$} \\
\hline None & $\begin{array}{l}16 \\
6\end{array}$ & $\begin{array}{l}94.1 \\
54.5\end{array}$ & 33.9 (30.0-37.8) & - & 0.261 \\
\hline$\leq 3$ & 6 & 54.5 & $25.1(15.5-34.5)$ & $36(0.7-71.2)$ & \\
\hline$>3$ & 21 & 75.0 & $29.8(25.6-33.0)$ & $34(-)$ & \\
\hline
\end{tabular}

PFS, progression-free survival; $\mathrm{Cl}$, confidence interval 
Figure 1. PFS probability based on residue
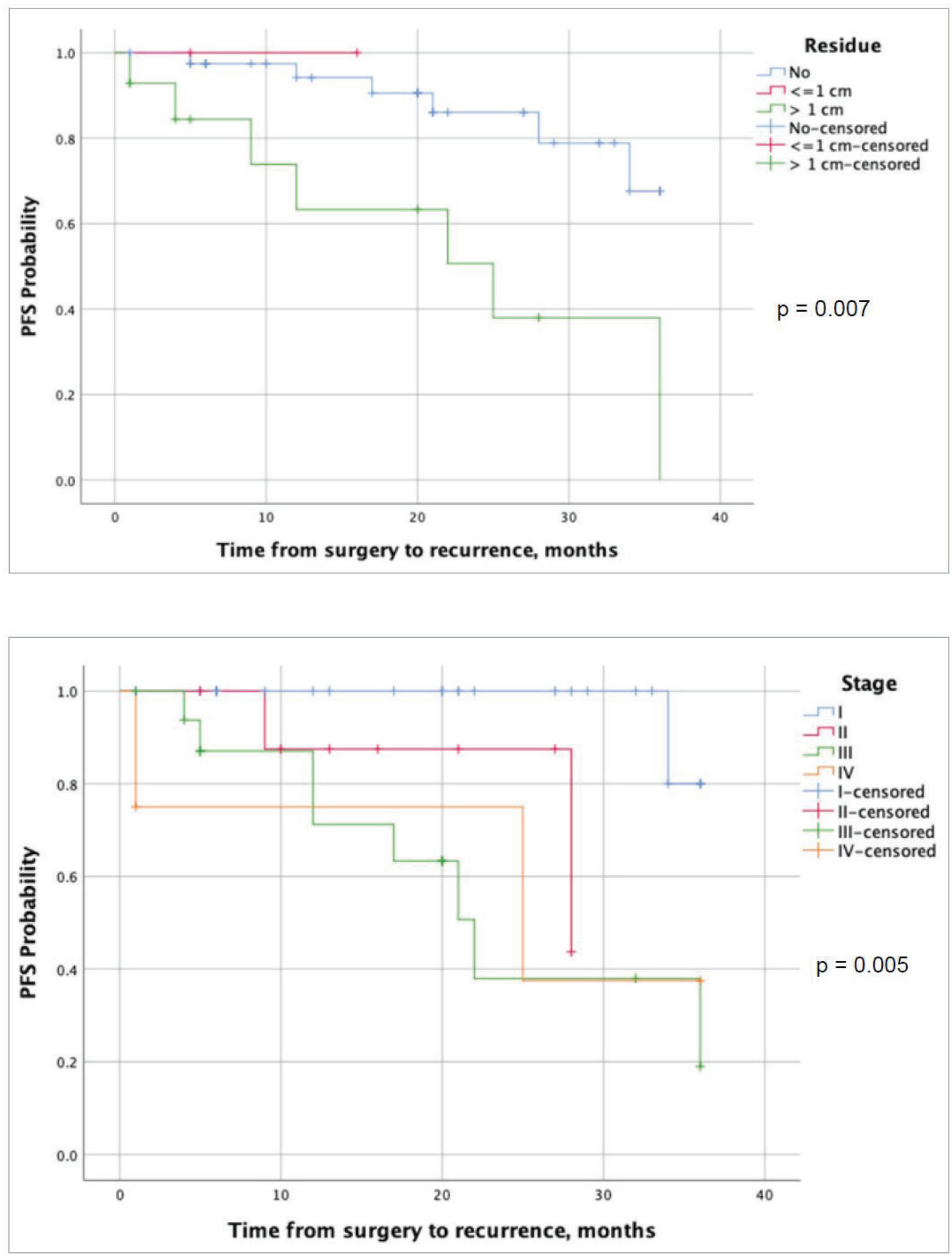

Figure 2. PFS probability based on stage 
Table 2. Cox regression analysis of characteristics and

recurrence

\begin{tabular}{|c|c|c|c|c|c|c|}
\hline Characteristics & $\mathbf{N}$ total & $\begin{array}{c}\text { Recurrence, } \\
\%\end{array}$ & $\mathbf{P}$ & $\begin{array}{l}\text { Univariate HR } \\
(95 \% \mathrm{Cl})\end{array}$ & $\mathbf{P}$ & $\begin{array}{c}\text { Multivariate HR } \\
(95 \% \mathrm{CI})\end{array}$ \\
\hline \multicolumn{7}{|l|}{ Age: } \\
\hline$\leq 60$ y.o. & 37 & 27.0 & & 1 & & \\
\hline > 60 y.o. & 19 & 15.8 & 0.636 & $0.7(0.2-2.7)$ & & \\
\hline \multicolumn{7}{|l|}{ Residue: } \\
\hline No residue & 40 & 15.0 & 0.020 & 1 & 0.365 & 1 \\
\hline$\leq 1 \mathrm{~cm}$ & 2 & 0.0 & 0.988 & $0.000(0.000)$ & 0.988 & $0.000(0.000)$ \\
\hline$>1 \mathrm{~cm}$ & 14 & 50.0 & 0.005 & $4.8(1.6-14.3)$ & 0.156 & $2.3(0.7-7.1)$ \\
\hline \multicolumn{7}{|l|}{ Stage: } \\
\hline 1 & 26 & 3.8 & 0.059 & 1 & 0.145 & 1 \\
\hline ॥ & 9 & 22.2 & 0.093 & $7.9(0.7-88.7)$ & 0.134 & $6.5(0.6-75.7)$ \\
\hline III & 17 & 47.1 & 0.008 & $16.9(2.1-136.3)$ & 0.023 & $12.2(1.4-105.4)$ \\
\hline IV & 44 & 50.0 & 0.033 & $13.8(1.2-153.8)$ & 0.061 & $10.4(0.8-120.8)$ \\
\hline \multicolumn{7}{|l|}{ Histopathology: } \\
\hline Serous & 16 & 31.3 & 0.692 & 1 & & \\
\hline Mucinous & 16 & 6.3 & 0.237 & $0.3(0.1-2.4)$ & & \\
\hline Clear cell & 8 & 25.0 & 0816 & $0.8(0.2-4.6)$ & & \\
\hline Endometrioid & 14 & 35.7 & 0.622 & $1.1(0.4-4.9)$ & & \\
\hline Seromucinous & 2 & 0.0 & 0.988 & $0.000(0.000)$ & & \\
\hline \multicolumn{7}{|l|}{ Grade: } \\
\hline I & 30 & 16.7 & 0.551 & 1 & & \\
\hline II & 12 & 33.3 & 0.986 & $0.9(0.3-3.7)$ & & \\
\hline III & 14 & 28.6 & 0.359 & $1.9(0.5-8.1)$ & & \\
\hline \multicolumn{7}{|c|}{$\begin{array}{l}\text { Number of } \\
\text { chemotherapy cycles: }\end{array}$} \\
\hline None & 17 & 5.9 & 0.301 & $1.8(0.6-5.7)$ & & \\
\hline$\leq 3$ & 11 & 45.5 & 0.359 & $0.4(0.1-3.1)$ & & \\
\hline$>3$ & 28 & 25.0 & 0.313 & 1 & & \\
\hline
\end{tabular}

HR, hazard ratio

Table 3.

Kaplan-Meier and log-rank analysis of 3-year survival

\begin{tabular}{|c|c|c|c|c|c|}
\hline Characteristics & $\stackrel{\mathbf{N}}{\text { Survived }}$ & $\begin{array}{c}\text { 3-year survival, } \\
\%\end{array}$ & $\begin{array}{l}\text { Mean survival, } \\
\text { months }(95 \% \mathrm{Cl})\end{array}$ & $\begin{array}{l}\text { Median survival, } \\
\text { months }(95 \% \mathrm{Cl})\end{array}$ & $\begin{array}{l}P \text { value } \\
\text { log- rank }\end{array}$ \\
\hline \multicolumn{6}{|l|}{ Age: } \\
\hline$\leq 60$ y.o. & 21 & 56.8 & $28.7(25.1-32.2)$ & - & \multirow[t]{2}{*}{0.367} \\
\hline > 60 y.o. & 9 & 47.4 & $24.2(3.5-17.3)$ & $(-)$ & \\
\hline \multicolumn{6}{|l|}{ Residue: } \\
\hline No residue & 26 & 65.0 & $31.2(28.2-34.1)$ & - & \multirow[t]{3}{*}{0.001} \\
\hline$\leq 1 \mathrm{~cm}$ & 1 & 50 & $20.5(0.0-41.9)$ & $5(-)$ & \\
\hline$>1 \mathrm{~cm}$ & 3 & 21.4 & $16.7(9.3-24.2)$ & $12(6.5-17.5)$ & \\
\hline \multicolumn{6}{|l|}{ Stage: } \\
\hline 1 & 21 & 80.8 & $32.9(29.3-36.6)$ & $(-)$ & \multirow[t]{4}{*}{$<0.001$} \\
\hline II & 5 & 55.6 & $28.1(21.7-34.5)$ & $(-)$ & \\
\hline III & 3 & 17.6 & $20.8(14.4-27.3)$ & $21(7.5-34.4)$ & \\
\hline IV & 1 & 25.0 & $14.5(0.2-28.8)$ & $1(-)$ & \\
\hline \multicolumn{6}{|l|}{ Histopathology: } \\
\hline Serous & 6 & 62.5 & $25.9(19.3-32.6)$ & $34(23.5-44.5)$ & \multirow[t]{5}{*}{$<0.001$} \\
\hline Mucinous & 11 & 68.8 & $30.8(25.8-35.7)$ & - & \\
\hline Clear cell & 5 & 62.5 & $28.6(20.6-36.6)$ & - & \\
\hline Endometrioid & 8 & 57.1 & $27.2(20.0-34.4)$ & - & \\
\hline Seromucinous & 0 & 0 & $2.5(0.0-5.4)$ & $1(-)$ & \\
\hline \multicolumn{6}{|l|}{ Grade: } \\
\hline I & 17 & 56.7 & $26.8(22.1-31.5)$ & - & \multirow[t]{3}{*}{0.713} \\
\hline II & 5 & 41.7 & $26.2(18.8-33.5)$ & $31(3.8-58.1)$ & \\
\hline III & 8 & 57.1 & $28.9(21.8-36.1)$ & - & \\
\hline \multicolumn{6}{|c|}{$\begin{array}{l}\text { Number of } \\
\text { chemotherapy cycles: }\end{array}$} \\
\hline None & 11 & 64.7 & $26.3(18.4-34.2)$ & - & \multirow[t]{3}{*}{0.031} \\
\hline$\leq 3$ & 2 & 18.2 & $21.8(13.5-30.2)$ & $18(1.2-34.8)$ & \\
\hline$>3$ & 17 & 60.7 & $29.8(26.4-33.2)$ & - & \\
\hline
\end{tabular}


Figure 3. Survival probability based on residue

Figure 4. Survival probability based on stage
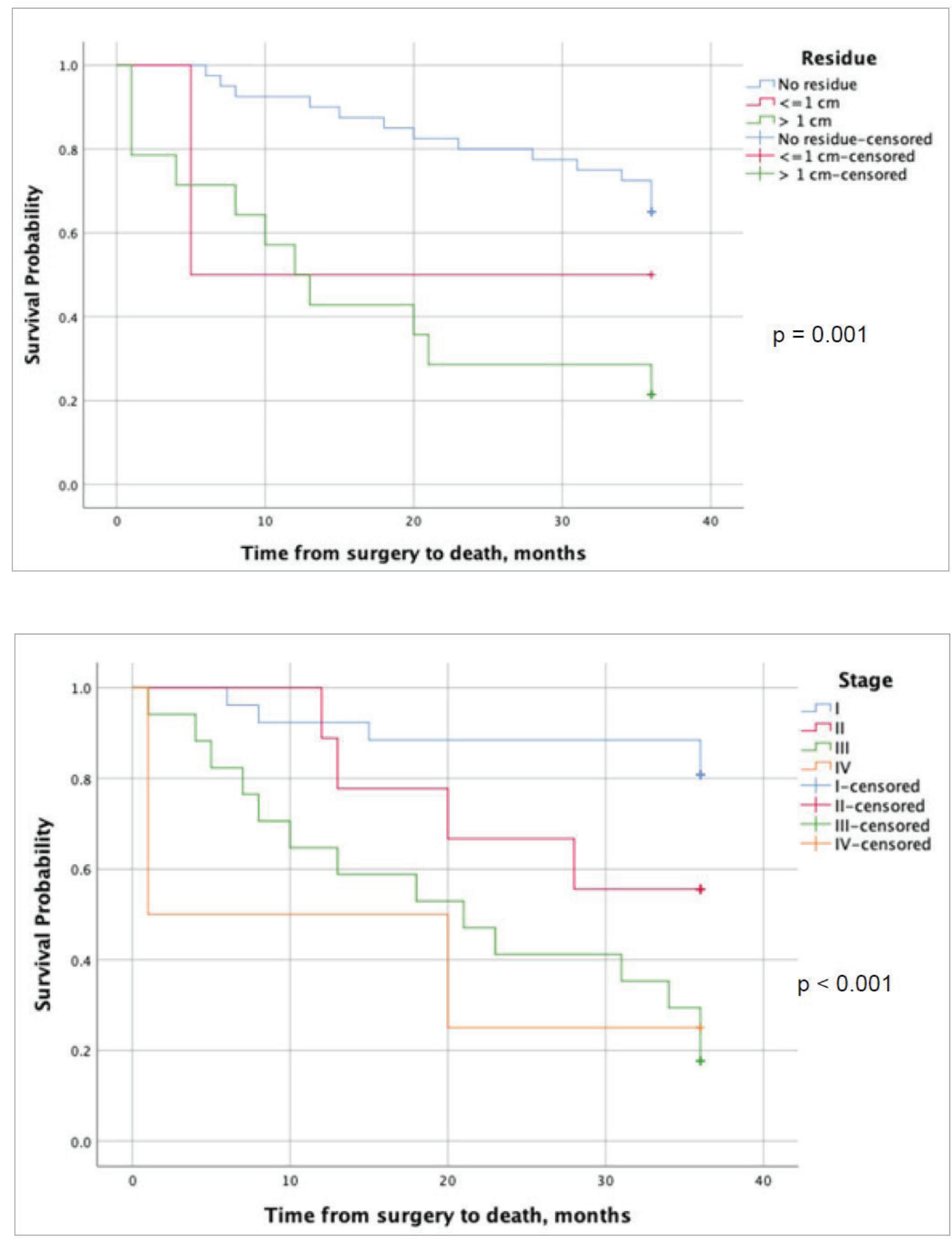
Figure 5. Survival probability based on histopathology

Figure 6. Survival probability based on number of chemotherapy cycles
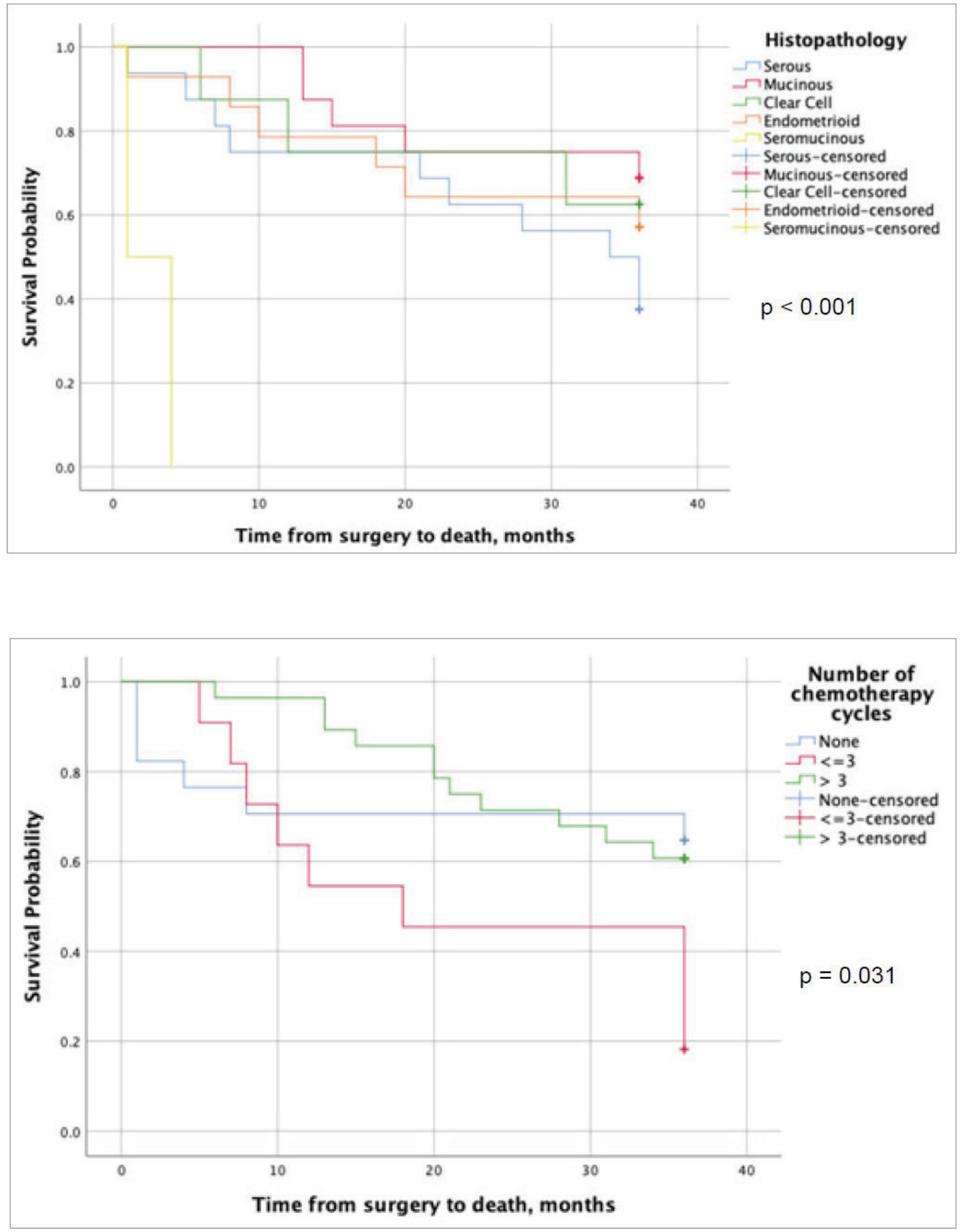
Table 4. Cox regression analysis of characteristics and mortality

\begin{tabular}{|c|c|c|c|c|c|c|}
\hline Category & $\mathbf{N}$ total & Death, \% & $\mathbf{P}$ & $\begin{array}{l}\text { Univariate HR } \\
(95 \% \mathrm{Cl})\end{array}$ & $\mathbf{P}$ & $\begin{array}{l}\text { Multivariate HR } \\
(95 \% \mathrm{Cl})\end{array}$ \\
\hline \multicolumn{7}{|l|}{ Age: } \\
\hline$\leq 60$ y.o. & 37 & 43.2 & & 1 & & \\
\hline > 60 y.o. & 19 & 52.6 & 0.373 & $1.4(0.6-3.2)$ & & \\
\hline \multicolumn{7}{|l|}{ Residue: } \\
\hline No residue & 40 & 35.0 & 0.003 & 1 & & \\
\hline$\leq 1 \mathrm{~cm}$ & 2 & 50.0 & 0.455 & $2.2(0.3-16.5)$ & & \\
\hline$>1 \mathrm{~cm}$ & 14 & 78. & 0.001 & $4.0(1.8-8.9)$ & & \\
\hline \multicolumn{7}{|l|}{ Stage: } \\
\hline 1 & 26 & 19.2 & 0.001 & 1 & 0.007 & 1 \\
\hline II & 9 & 44.4 & 0.129 & $2.7(0.7-10.4)$ & 0.083 & $5.9(0.8-44.1)$ \\
\hline III & 17 & 82.4 & 0.000 & $7.1(2.5-19.7)$ & 0.005 & $15.0(2.3-98.7)$ \\
\hline IV & 4 & 75.0 & 0.003 & $8.6(2.0-36.3)$ & 0.001 & $43.6(4.5-417.9)$ \\
\hline \multicolumn{7}{|l|}{ Histopathology: } \\
\hline Serous & 16 & 62.5 & 0.007 & 1 & 0.200 & 1 \\
\hline Mucinous & 16 & 31.3 & 0.103 & $0.4(0.1-1.2)$ & 0.116 & $4.6(0.7-30.9)$ \\
\hline Clear cell & 8 & 37.5 & 0.359 & 0.5 (0.2-1.9) & 0.076 & $4.1(0.8-19.1)$ \\
\hline Endometrioid & 14 & 42.9 & 0.386 & $0.6(0.2-1.7)$ & 0.589 & $1.3(0.4-4.5)$ \\
\hline Seromucinous & 2 & 100 & 0.003 & $21.0(2.7-160.1)$ & 0.026 & $20.1(0.9-408.6)$ \\
\hline \multicolumn{7}{|l|}{ Grade: } \\
\hline I & 30 & 43.3 & 0.721 & 1 & & \\
\hline II & 12 & 68.3 & 0.872 & $1.1(0.4-2.8)$ & & \\
\hline III & 14 & 42.9 & 0.467 & $1.5(0.5-4.5)$ & & \\
\hline \multicolumn{7}{|c|}{$\begin{array}{l}\text { Number of } \\
\text { chemotherapy cycles: }\end{array}$} \\
\hline None & 17 & 35.3 & 0.045 & $1.0(0.4-2.7)$ & 0.072 & $2.2(0.3-17.2)$ \\
\hline$\leq 3$ & 11 & 81.8 & 1,000 & $2.8(1.2-6.8)$ & 0.459 & $3.6(1.2-11.5)$ \\
\hline$>3$ & 28 & 39.3 & 0.022 & 1 & 0.028 & 1 \\
\hline
\end{tabular}

$\mathrm{HR}$, hazard ratio

\section{DISCUSSION}

As shown by Kaplan-Meier and Cox regression analyses, age had no association with PFS or ovarian cancer recurrence, respectively. However, Winter et al. [6] reported that age influenced the progression of epithelial ovarian cancer but was limited to stage III. In addition, every 10-year increase in age was associated with a $6 \%$ increase in disease progression. The difference might have been due to our sample inclusion of all stages of epithelial ovarian cancer, while their sample was limited to stage III.

Besides, the 3 -year survival rate was $56.8 \%$ at age $\leq 60$ years and $47.4 \%$ at age $>60$ years, with mean survivals of 28.7 months and 24.2 months, respectively. However, this result was not statistically significant (P-value of $>0.05$ ) in either Kaplan-Meier or Cox regression analyses. In a study of prognostic factors in stage III and IV epithelial ovarian cancer, Balley et al. [7] found that women $<60$ years of age had a longer survival rate than other age groups.

Kaplan-Meier analysis revealed that residue and PFS had a statistically significant association. However, the mean and median PFS values could not be determined because all patients with residue $\leq 1 \mathrm{~cm}$ were included in the censored data, and none had a recurrence.

The 3-year PFS was $85 \%$ in patients with no residue (34 patients had no recurrence) and $15 \%$ in patients with recurrence (six patients had recurrence). The two patients with residue $\leq 1 \mathrm{~cm}$ had $100 \%$ PFS and no recurrence. In addition, patients with residue $>1 \mathrm{~cm}$ had $50.0 \%$ PFS (seven patients with and seven patients without recurrence). Kaplan-Meier and the log-rank test also revealed a significant association, yet Cox regression analysis did not, perhaps due to the limited sample distribution in residue size.

In a retrospective study of 83 patients with epithelial ovarian cancer at all stages by Baker et al. [8], 44 patients (53\%) were found to have optimal debulking (without residue or residue $<2 \mathrm{~cm}$ ), while 39 patients $(47 \%)$ had suboptimal debulking (residue $>2 \mathrm{~cm}$ ). The median PFS value for patients with optimal debulking was 27.3 months, while for patients with suboptimal debulking, it was 22.3 months.

Winter et al. [6] reported that residue influenced the recurrence of epithelial ovarian cancer, but their 
study was limited to stage III subjects. In addition, residue had a significant association with PFS outcome, as revealed by Cox regression analysis. Furthermore, the presence of a residue $>1 \mathrm{~cm}$ had twice the likelihood of recurrence, as compared to no residue (microscopic residue).

In our study, the univariate analysis uncovered a significant association between residue and recurrence, but the significance was not retained by multivariate analysis. This finding was likely because residue had less influence than the disease stage. Patients with no residue had the highest mean survival (31.2 months) and 3 -year survival of $56.8 \%$. Besides, patients with residue $\leq 1 \mathrm{~cm}$ had a mean survival of 20.5 months and 3-year survival of $50 \%$, while those with residue > $1 \mathrm{~cm}$ had the lowest mean survival (16.7 months) and 3 -year survival of $21.4 \%$. Regarding this, univariate analysis revealed a significant association between residue and mortality, but Cox regression multivariate analysis did not retain significance.

The presence of residue indicates that surgery was suboptimal. Marszalek et al. [9] in 2010 found that suboptimal surgery or residual tumors had an HR of 2.2. In addition, Winter et al. [6] noted that the presence of postoperative residues was significantly associated with increased mortality, with HR of 2.47 for residues $>1 \mathrm{~cm}$ compared to microscopic residues $(H R=1)$. Furthermore, Baker et al. [8] unveiled a significant association between debulking surgery and survival $(P=0.003)$. The median overall survival was 51.5 months for optimal debulking and 40.8 months for suboptimal debulking.

Kaplan-Meier analysis showed a significant association between stage and PFS. In patients with stage I, the median PFS value could not be determined because the stage I curve did not exceed the PFS probability value of 0.5 or $50 \%$. Nevertheless, patients with stages II, III, and IV had median PFS values of 28 months, 22 months, and 25 months, respectively. Also, the mean PFS values of stages I, II, III, and IV were 35.6 months, 25.6 months, 22.9 months, and 23.1 months, respectively.

Moreover, multivariate analysis of stages I, II, III, and IV and recurrence yielded HRs of 1 (reference value), 6.5 (Cl 95\% 0.6-75.7, P-value 0.134), $12.2(\mathrm{Cl} 95 \%$ 1.4-105.4, P-value 0.023), and 10.4 (Cl 95\% 0.8-120.8, $\mathrm{P}$-value 0.061$)$, respectively. This finding indicates that patients with stage IV epithelial ovarian cancer had a 10.4 greater risk of recurrence. The higher stage III HR might have been due to that groups having received inadequate chemotherapy. Alternatively, several stage III subjects had diabetes mellitus, which could negatively affect PFS.

These results are consistent with the clinical perspective that the more advanced stage has a more extensive disease, for which optimal debulking surgery is more complicated. Hence, suboptimal surgery in stages III and IV may lead to postoperative residue, which eventually affects PFS [6].

Baker et al. [8] found a significant association between stage and PFS ( $P=0.001)$ in a study of 83 patients with epithelial ovarian cancer [stage I: 11 patients $(13.3 \%)$, stage II: two patients $(2.4 \%)$, stage III: 49 patients (58\%), and stage IV: 21 patients (25.3\%)]. Median PFS was 40.3 months at the early stage and 20.5 months at the advanced stage. They also uncovered that the higher the stage, the lower the mean/median survival, recurrence, and overall survival.

Of 26 patients with stage I, five patients (19.2\%) died, and 21 patients (80.8\%) survived. Of nine patients with stage II, four patients (44.4\%) died, and five patients $(55.6 \%)$ survived. In addition, of 17 patients with stage III, 14 patients (82.4\%) died, and three patients (17.6\%) survived. Of 4 patients with stage IV, three patients (75.0\%) died, and one patient $(25.0 \%)$ survived.

Patients with stage I had the highest mean survival (32.9 months) and 3-year survival of $80.8 \%$. In addition, patients with stage II had a mean survival of 28.1 months and 3-year survival of $55.6 \%$, while patients with stage III had a mean survival of 20.8 months and 3-year survival of $17.6 \%$. Lastly, patients with stage IV had the lowest mean survival (14.5 months) and 3-year survival of $25.0 \%$. Multivariate analysis yielded the following HRs: stage I HR = 1 (reference value), stage II HR = $5.9(\mathrm{Cl} 95 \%$ 0.8-44.1, P-value 0.083), stage III $\mathrm{HR}=14.4(\mathrm{Cl} 95 \%$ 2.3-98.7, P-value 0.001), and stage IV HR $=42.5(\mathrm{Cl} 95 \%$ 4.5-417.9, P-value 0.0026). As such, patients with stage IV epithelial ovarian cancer had a 42.5 times greater risk of death, which was in agreement with the stage IV 3 -year survival of only $25 \%$.

A recent study reported that ovarian cancer usually appears at an advanced stage when 5-year survival is only $30.2 \%$. Some cases (16\%) were diagnosed with localized tumors (stage 1) when the 5-year-survival was $92.6 \%[2]$.

In a study on patients with epithelial ovarian cancer in North America between 1994-1996, O'Malley et al. [10] showed that the 5-year survival rate was strongly influenced by stage. Patients had 5-year survival rates of $82 \%$ at stage IC, $57 \%$ at stage II, $28 \%$ at stage III, and $10 \%$ at stage IV. Stages III and IV had low 5-yearsurvival, with hazard ratios ranging from 8 to 11.8 compared to stage IC.

Both Kaplan-Meier and Cox regression revealed no significant association between histopathology, PFS, and recurrence, respectively. In contrast, Winter et al. [6] reported that histopathology type had a significant association with PFS and recurrence in univariate and multivariate analyses. Mucinous type had $H R=2.18$, while serous had HR = 1 (reference value).

Moreover, Oliver et al. [11] noted that in patients with clear cell and serous carcinoma who were given platinum-based chemotherapy, the PFS of the clear cell 
type was better at early stages (I and II) than that of the serous type. However, at advanced stages (III and IV), the PFS of the clear cell type was worse than that of the serous type. Our lack of histopathology association might have been due to the dominant effect of the stage in determining PFS compared to other characteristics.

Patients with mucinous histopathology had the highest mean survival (30.8 months) and 3-year survival of $68.8 \%$. In addition, patients with serous histopathology had a mean survival of 25.9 months and 3-year survival of $62.5 \%$, and patients with endometrioid histopathology had a mean survival of 27.2 months and 3-year survival of $57.1 \%$. Lastly, patients with seromucinous histopathology had the lowest mean survival (2.5 months) and a 3-year survival rate of $0 \%$.

Further, multivariate analysis yielded the following HRs: serous $H R=1$ (reference value), mucinous $H R=$ 4.6 (Cl 95\% 0.7-30.9, P-value 0.116), clear cell HR = 4.1 (Cl 95\% 0.8-19.1, P-value 0.076), endometrioid HR = 1.3 (Cl 95\% 0.4-4.5, P-value 0.589), and seromucinous $\mathrm{HR}=20.1$ (Cl 95\% 0.9-408.6, P-value 0.026).

In a study of stage IV epithelial ovarian cancer with mucinous and clear cells, overall survival was worse than serous type [6]. In addition, Chang et al. [12] found that endometrioid histopathological type was significantly associated with overall survival at an advanced stage but not at an early stage.

Both Kaplan-Meier and Cox regression uncovered no significant association between grade, PFS, and recurrence, respectively. Winter et al. reported similarly. However, in univariate and multivariate analyses, the grade was statistically significant, but $H R$ values for each grade were not much different [grade III: $H R=1.07$; grade II: $H R=1.1$, and grade I: $H R=1$ (reference value)] [6]. Again, our lack of association might have been due to the dominant influence of the stage on PFS.

The 3-year survival rates for grades I, II, and III were $56.7 \%, 41.7 \%$, and $57.1 \%$, respectively. However, this result was not statistically significant ( $P>0.05$ ). Cox regression analysis also showed that tumor grade was not significant in determining mortality in patients with epithelial ovarian cancer. In contrast, Winter et al. found that tumor grade was statistically significant in the overall survival analysis. However, univariate and multivariate analyses revealed no significant results $(P>0.05)[6]$.

In this case, the grade indicates the degree of cellular differentiation. It has long been considered to be an influencing factor on tumor 'behavior' and survival. This notion derives from the understanding that poor cellular differentiation represents a higher degree of mitotic aberration, which is interpreted to be comparable to the more aggressive 'behavior' of cancer cells. However, there is conflicting evidence regarding an association between tumor grade and clinical outcome $[6,13,14]$.
Of 17 patients who did not undergo chemotherapy, one patient $(5.9 \%)$ experienced recurrence, while 16 patients $(94.1 \%)$ had no recurrence. Eleven of these patients had stage I, while there were two patients, each with stages III and IV. One of the recurrence patients with stage IV had only one follow-up control visit, at which time a residual mass was detected during clinical evaluation. Besides, from the 11 patients who underwent $\leq 3$ chemotherapy cycles, five patients (45.5\%) experienced recurrence, and six patients (54.5\%) had no recurrence. Of the 28 patients who underwent $>3$ chemotherapy cycles, seven patients (25.0\%) experienced recurrence, while 21 patients $(75.0 \%)$ had no recurrence.

Kaplan-Meier analysis also revealed no significant association between the number of chemotherapy cycles and PFS. Baker et al. [8] reported that the median PFS in patients with epithelial ovarian cancer with all stages who received/underwent first-line chemotherapy was 17 months. They also noted that the median PFS in patients who underwent chemotherapy was 11 to 21 months.

Moreover, patients who did not undergo chemotherapy had a mean survival of 26.3 months and a 3-year survival rate of $64.7 \%$. It is crucial to note that 11 such patients had stage I, which generally required only postoperative follow-up. Also, all 11 patients lived. In addition, two patients with stage III and two patients with stage IV planned to receive postoperative adjuvant chemotherapy, but they died before treatment.

A total of 11 patients received $\leq 3$ chemotherapy series, of whom nine patients $(81.8 \%)$ died, and two patients (18.2\%) lived; thus, their 3-year survival was $18.2 \%$. Meanwhile, a total of 28 patients received $>3$ chemotherapy series, of whom 11 patients (39.3\%) died, and 17 patients (60.7\%) lived; hence, their 3-year survival was $60.7 \%$. Mean survival was 21.8 months for those who received $<3$ chemotherapy cycles and 29.8 months for those who received $>3$ cycles. The former had a 3-year survival of $18.2 \%$.

In addition, the multivariate analysis yielded the following $H R$ values: $H R=2.2$ for those who did not receive chemotherapy, $H R=3.6$ for those who received $<3$ cycles, and $\mathrm{HR}=1$ for those who received $>3$ cycles (reference value).

At RSUP Cipto Mangunkusumo, the 4-year survival was $77 \%$ for the epithelial type, $83.3 \%$ for the germinal type, and $100 \%$ for the stromal type. Regarding therapy, the 4 -year survival was $84.1 \%$ for surgery alone, $83.3 \%$ for adjuvant therapy, and $68.4 \%$ for neoadjuvant chemotherapy [15].

In addition, a study in Taiwan showed that the administration of taxane-based chemotherapy had a significant association with better overall survival in patients with early and advanced-stage epithelial ovarian cancer [12]. 


\section{CONCLUSIONS}

Residue and stage characteristics had statistically significant associations with PFS and can be predictors for the disease recurrence. However, age, histopathology, grade, and the number of chemotherapy cycles had no such associations. In addition, residue, stage, histopathology, and the number of chemotherapy cycles had significant associations to 3-year survival, but only the stage, histopathology, and the number of chemotherapy cycles can be useful predictors for mortality.

\section{DECLARATIONS}

\section{Ethics Approval and Consent to Participate}

This research received ethical clearance from the Health Research Ethics Committee at RSUD Dr. Soetomo Surabaya with reference number 0077/KEPK/IX/2020. All subjects provided written informed consent before interviews and data collection.

\section{Competing of Interest}

The authors declare no competing interest in this study.

\section{Research Funding}

This research had no sponsorship and was fully funded by the researchers.

\section{Acknowledgment}

We would especially like to acknowledge our co-author, the late Dr. Budiono, who passed away in December 2020, for his support for this work. He will be greatly missed by friends and colleagues.

\section{REFERENCES}

1. Sung H, Ferlay J, Siegel RL, et al. Global cancer statistics 2020: GLOBOCAN estimates of incidence and mortality worldwide for 36 cancers in 185 countries. CA Cancer J Clin. 2021;71(3):209-249.

2. Howlader $N$, Noone $A M$, Krapcho $M$, et al. SEER Cancer Statistics Review, 1975-2017 [Internet]. Bethesda: National Cancer Institute; 2020 [cited 2021 Jan 30]. Available from: https://seer.cancer. gov/csr/1975-2017/

3. Ayuningtyas $\mathrm{A}$, Hartono $\mathrm{P}$, Nugroho $\mathrm{H}$. Characteristic of ovarian cancer deaths in Dr. Soetomo Hospital during 2015-2017. In: Case Presentation, Department of Obstetric Gynecology, Faculty of Medicine, Universitas Airlangga, RSUD dr. Soetomo, Surabaya; 2018. p. 1-2.
4. Meinhold-Heerlein I, Fotopoulou C, Harter P, et al. The new WHO classification of ovarian, fallopian tube, and primary peritoneal cancer and its clinical implications. Arch Gynecol Obstet. 2016;293(4):695700.

5. Prat J; FIGO Committee on Gynecologic Oncology. FIGO's staging classification for cancer of the ovary, fallopian tube, and peritoneum: abridged republication. J Gynecol Oncol. 2015;26(2):87-9.

6. Winter WE, Maxwell GL, Tian C, et al. Gynecologic Oncology Group Study. Prognostic factors for stage III epithelial ovarian cancer: a Gynecologic Oncology Group Study. J Clin Oncol. 2007;25(24):3621-7.

7. Bailey J, Murdoch J, Anderson R, et al. Stage III and IV ovarian cancer in the South West of England: five-year outcome analysis for cases treated in 1998. Int J Gynecol Cancer. 2006;16 Suppl 1:25-9.

8. Aziz KKA, Shehata MA, Ghany AEA, et al. Retrospective study of epithelial ovarian cancer in the Oncology Department, Menoufia University. Menoufia Med J. 2014;27(4):650.

9. Marszalek A, Alran S, Scholl S, et al. Outcome in advanced ovarian cancer following an appropriate and comprehensive effort at upfront cytoreduction: a twenty-year experience in a single cancer institute. Int J Surg Oncol. 2010;2010:214919.

10. O'Malley CD, Cress RD, Campleman SL, Leiserowitz GS. Survival of Californian women with epithelial ovarian cancer, 1994-1996: a population-based study. Gynecol Oncol. 2003;91(3):608-15.

11. Oliver KE, Brady WE, Birrer $M$, et al. An evaluation of progression free survival and overall survival of ovarian cancer patients with clear cell carcinoma versus serous carcinoma treated with platinum therapy: An NRG Oncology/Gynecologic Oncology Group experience. Gynecol Oncol. 2017;147(2):243-249.

12. Chang LC, Huang CF, Lai MS, et al. Prognostic factors in epithelial ovarian cancer: A population-based study. PLoS One. 2018;13(3):e0194993.

13. Eisenkop SM, Friedman RL, Wang HJ. Complete cytoreductive surgery is feasible and maximizes survival in patients with advanced epithelial ovarian cancer: a prospective study. Gynecol Oncol. 1998;69(2):103-8.

14. Chan JK, Loizzi V, Lin YG, et al. Stages III and IV invasive epithelial ovarian carcinoma in younger versus older women: what prognostic factors are important?. Obstet Gynecol. 2003;102(1):156-61.

15. Noela F, Nuryanto KH. Epidemiology data of ovarian cancer in Dr. Cipto Mangunkusumo Hospital, Jakarta. Indones J Obstet Gynecol. 2016;4(2):101. 